\title{
Understanding barriers to optimal medication management for those requiring long-term dialysis: rationale and design for an observational study, and a quantitative description of study variables and data
}

Trudi Aspden ${ }^{1 *}$, Martin J Wolley ${ }^{2}$, Tian M Ma ${ }^{3}$, Edwin Rajah ${ }^{4}$, Samantha Curd ${ }^{5}$, Dharni Kumar ${ }^{5}$, Sophia Lee ${ }^{5}$, Krenare Pireva ${ }^{5}$, Olita Taule'alo ${ }^{5}$, Porsche Tiavale ${ }^{5}$, Angela L Kam ${ }^{6}$, Jun S Suh ${ }^{3}$, Julia Kennedy ${ }^{1}$ and Mark R Marshall ${ }^{7^{*}}$

\begin{abstract}
Background: Rates of medication non-adherence in dialysis patients are high, and improving adherence is likely to improve outcomes. Few data are available regarding factors associated with medication adherence in dialysis patients, and these data are needed to inform effective intervention strategies.

Methods/design: This is an observational cross-sectional study of a multi-ethnic dialysis cohort from New Zealand, with the main data collection tool being an interviewer-assisted survey. A total of 100 participants were randomly sampled from a single centre, with selection stratified by ethnicity and dialysis modality (facility versus home). The main outcome measure is self-reported medication adherence using the Morisky 8-Item Medication Adherence Scale (MMAS-8). Study data include demographic, clinical, social and psychometric characteristics, the latter being constructs of health literacy, medication knowledge, beliefs about medications, and illness perceptions. Psychometric constructs were assessed through the following survey instruments; health literacy screening questions, the Medication Knowledge Evaluation Tool (Okuyan et al.), the Beliefs about Medication Questionnaire (Horne et al.), the Brief Illness Perception Questionnaire (Broadbent et al.). Using the study data, reliability analysis for internal consistency is satisfactory for the scales evaluating health literacy, medication knowledge, and beliefs about medications, with Chronbach's a $>0.7$ for all. Reliability analysis indicated poor internal consistency for scales relating to illness perceptions. MMAS-8 and all psychometric scores are normally distributed in the study data.
\end{abstract}

Discussion: This study will provide important information on the factors involved in medication non-adherence in New Zealand dialysis patients. The resulting knowledge will inform long-term initiatives to reduce medication non-adherence in dialysis patients, and help ensure that they are addressing appropriate and evidence based targets for intervention.

Keywords: Medication adherence, Dialysis, Health literacy, Medication knowledge, Beliefs about medications, Illness perception

\footnotetext{
* Correspondence: t.aspden@auckland.ac.nz; mrmarsh@woosh.co.nz

'School of Pharmacy, Faculty of Medical and Health Sciences, The University

of Auckland, 85 Park Rd, Auckland 1142, New Zealand

${ }^{7}$ School of Medicine, Faculty of Medical and Health Sciences, The University

of Auckland, 85 Park Rd, Auckland 1142, New Zealand

Full list of author information is available at the end of the article
} 


\section{Background}

Adherence of patients to prescribed medications is an issue of concern to payers, policymakers, providers and healthcare professionals. Non-adherence is highly prevalent [1], expensive to health systems [2], and associated with poorer outcomes for many chronic diseases [3-5].

In patients with end stage kidney disease, dialysis is an effective treatment for the removal of most uremic toxins, although the majority of patients require a large number of additional medications to control hyperphosphatemia, hypertension, anaemia and other biochemical consequences of their disease. Furthermore, patients often have other comorbid conditions that require treatment. The total drug burden in dialysis patients can be considerable, with the median number of prescribed tablets per day ranging from 12 to 19 in recent observational studies, the highest burden of any chronic disease group [6, 7]. Medication non-adherence within this group is unsurprisingly high (Table 1). A recent systematic review of the literature appraised 19 widely divergent studies, and reported the prevalence of non-adherence to be between 3 to $80 \%$ (depending on definition), with a median of $50 \%$ [8]. In a previous pilot study into medication non-adherence among haemodialysis patients at our institution, nonadherence rates were $33 \%$ and several fold higher amongst New Zealand (NZ) Māori, Pacific Peoples and the elderly [9].

The consequences of medication non-adherence have not been well established in dialysis populations. Most investigators infer changes in relative mortality risks from suboptimal blood pressure (non-adherence to antihypertensives), suboptimal serum phosphate (non-adherence to phosphate binders), and suboptimal haemoglobin (nonadherence to erythropoietin). Perhaps the most compelling data, however, can be found in a recent study aiming to reduce medication-related problems in haemodialysis patients through an integrated pharmacy program in a large United States dialysis organization. In a retrospective analysis, the mortality risk with an integrated pharmacy program (versus none) was 0.79 (95\% CI, 0.74-0.84), relative rate of hospital admission 0.93 (95\% CI, 0.90-0.96), and relative number of hospital days 0.86 (95\% CI, 0.82-0.90) [10]. There is therefore a strong signal that improved medication adherence might result in clinical benefits for the patient, and lower healthcare resource utilization for the country.

In other patient groups interventional strategies to improve medication adherence have been validated [11], but information specific to dialysis patients is lacking [12]. A major barrier to designing strategies to improve medication adherence in dialysis patients is the lack of knowledge about factors associated with adherence to drugs within this group. Demographic factors, clinical factors and psychosocial factors may all influence medication adherence, but whether these are important in dialysis patients is unclear [13]. There is therefore an exigent need to clarify the drivers of poor medication adherence in this patient group, to inform interventions and optimize their chances of being effective.

In this article, we describe the protocol for an observational study of medication adherence in a large multiethnic New Zealand cohort, in which we are studying self-reported medication adherence in relation to a variety of demographic, clinical, social, and psychometric factors. Of note, the psychometric constructs used for this study and the instruments with which they are assessed - are not well-described in dialysis populations, and distribution of construct scores and the reliability of the instruments cannot be assumed. As part of this article, therefore, we perform and report an interim analysis of the completed study dataset, with a view to ensuring appropriate use of these data in our subsequent statistical modelling.

\section{Methods/design}

\section{Study aim and hypothesis}

The broad aim of this study is to improve our understanding of the factors involved in medication non-adherence in dialysis patients, to inform the development of an intervention strategy. The specific objectives are to estimate self-reported medication adherence in this population, and explore the relationship between this outcome and patients' medication knowledge and beliefs, health literacy,

Table 1 Recent studies of drug non-adherence rates in dialysis populations

\begin{tabular}{|c|c|c|c|c|}
\hline First author of study (year) & Drug/treatment studied & Patient group & Rate of non adherence & Significant correlations \\
\hline Martins (2013) & Phosphate binders & Haemodialysis (502 patients) & $65.7 \%$ & $\begin{array}{l}\text { Cerebrovascular disease, } \\
\text { higher PTH, comprehension, } \\
\text { side effects }\end{array}$ \\
\hline Neri (2011) & Oral medications & Haemodialysis (1,238 patients) & $48 \%$ & $\begin{array}{l}\text { Perceived burden of } \\
\text { treatment, } \\
\text { number of tablets }\end{array}$ \\
\hline $\begin{array}{l}\text { Schmid (2009) } \\
\text { Systematic review }\end{array}$ & Oral medications & Haemodialysis (19 studies included) & $67 \%$ (range 3-80) & \\
\hline $\begin{array}{l}\text { Karamanidou (2008) } \\
\text { Systematic review }\end{array}$ & Phosphate binders & Dialysis (34 studies included) & Mean 51 \% (range $22-74 \%$ ) & $\begin{array}{l}\text { Younger age, psychosocial } \\
\text { beliefs }\end{array}$ \\
\hline
\end{tabular}


and illness perceptions. As part of the study, we will explore differences in these relationships by age, ethnicity, dialysis modality (facility based dependent versus homebased independent), and dialysis vintage (duration on dialysis since dialysis inception).

\section{Study design}

This is a cross-sectional study of a sample of prevalent dialysis patients from a single centre.

Demographic and clinical study data were collected from patients' clinical records (see case report form in Additional file 1), and directly from participant records in the Australia and New Zealand Dialysis and Transplant Registry (www.anzdata.org.au). Patient perceptions and beliefs were assessed using survey instruments administered as an in-person, interviewer-assisted questionnaire (see Additional file 2). As the interviews were not audiorecorded, they were conducted with pairs of interviewers for quality control purposes. Where possible, interviews were conducted in English, but professional interpreters were used if needed in the hospital setting.

The medication discussed in relation to the study was either a self administered erythropoiesis-stimulating agent, an angiotensin converting enzyme inhibitor, or a phosphate binder, depending on each participant's medication regimen.

Data collection was undertaken from $19^{\text {th }}$ July 2013 to $13^{\text {th }}$ June 2014, with database lock on $9^{\text {th }}$ November 2014.

\section{Setting}

The study setting is the Counties Manukau District Health Board (CMDHB) in Auckland, New Zealand. This is the largest dialysis programme in New Zealand, and provided care at the time of the study to approximately 550 patients, or $22 \%$ of that country's entire dialysis population [14]. The dialysis population reflects the general population, which is multi-ethnic with a high proportion of NZ Māori and Pacific Peoples, and socioeconomically disadvantaged (www.cmdhb.govt.nz). The prevalence of home dialysis is high in the programme, and $31 \%$ of dialysis patients are on peritoneal dialysis (PD) and $18 \%$ are on home haemodialysis (HD).

\section{Target population and eligibility criteria}

Eligible participants were those with end stage renal disease undergoing dialysis at $\mathrm{CMDHB}$ aged $\geq 16$ years old. Exclusion criteria include patients posing logistic or safety risks to interviewers; those suffering acute severe medical illness; those with severe communication difficulties (dysphasia, severe hearing impairment etc.); those who were unable to give direct informed consent.

\section{Recruitment of participants}

Participant selection was by computer-generated random selection from the service census. Selection was stratified by two factors to generate equally sized groups within 6 classifications, as defined by the following strata: recorded ethnicity from clinical records (NZ Māori versus Pacific Peoples versus "other" ethnicity), and location of dialysis (in a facility [in-centre HD] versus at home [home $\mathrm{HD}$ or $\mathrm{PD}])$.

\section{Power calculations}

A formal sample size was not calculated for this project, given the exploratory nature of the study. However, the rule of thumb to determine ratio of cases $(\mathrm{N})$ to instrumental variables $(\mathrm{m})$ is $\mathrm{N}>50+8(\mathrm{~m})$, subject to other factors such as alpha level and expected effect sizes $[15,16]$. Given the planned statistical approach, it was anticipated that a sample size of 100 participants in total would provide adequate power for most aspects of analysis.

\section{Research outcomes and endpoints}

The main outcome is self-reported medication adherence, as measured by the Morisky 8-Item Medication Adherence Scale (MMAS-8) [17]. This scale is a reliable and validated instrument, and is one of the most widely used tools to assess patient adherence [18-20]. It comprises eight items that address medication taking behaviour and (intentional and unintentional) adherence. The first seven items in the scale have dichotomous responses (yes/no), and the eighth item has 5 point Likert scale response, from $1=$ never to $5=$ all the time. The MMAS- 8 score ranges from 0 to 8 . Those who score less than 6 are considered to have low adherence, and those who score 6 or 7 are considered to have medium adherence, and those who score 8 high adherence.

\section{Quantitative variables}

The following demographic and clinical data were collected:

1) Demographics: We collected data about age, gender, ethnicity (prioritised according to accepted ethnicity data protocols [21-23]), relationship status, home ownership, and household composition, based on questions from the 2006 Statistics New Zealand Census. We assessed the socioeconomic status of the patient cohort using the NZDep score, which combines nine variables from the census that reflect eight domains of deprivation (income, home ownership, social support, employment, academic qualifications, living space, access to a telephone, access to a car). The index provides a score for each 
meshblock in New Zealand, which are defined geographical areas defined by Statistics New Zealand containing a median number of approximately 87 people in 2006. The NZDep score divides New Zealand into deciles, e.g. a value of 10 indicates the meshblock is in the most deprived $10 \%$ of the New Zealand population, and a value of 1 indicates that the meshblock is in the least deprived [24].

2) Clinical characteristics: We collected data about current modality of dialysis, dialysis vintage, history of previous transplantation, current dialysis dose (expressed as single pool Kt/V), age-adjusted Charlson Co-morbidity Index $[25,26]$, cause of end stage kidney disease, presence of diabetes mellitus, coronary artery disease, cerebrovascular disease, peripheral vascular disease, and lung disease.

The following study data were collected to evaluate the following psychometric constructs - health literacy, medication knowledge, beliefs about medication, and illness perceptions:

1) Health literacy: We assessed health literacy using a combination of three separate, single-item instruments (see Additional file 2, sections F and G). Each of these instruments has been validated against the S-TOFHLA (Short Test of Functional Health Literacy in Adults) and REALM (Rapid Estimate of Adult Literacy in Medicine) in the general population, and to a lesser degree the dialysis population $[27,28]$. The combination of three instruments has been used successfully with health literary assessments in a number of studies [29], including a large one of 1796 Veterans Administration patients [30]. We have previously assessed the validity and reliability of combining the three instruments in this study sample, supporting the use of the average of the individual scores as a single health literacy construct [31]. Those who score three or above on the final combined scale are considered to have marginal or poor health literacy.

2) Medication knowledge: We assessed patients' knowledge of medications using the Medication Knowledge Evaluation Tool (MKET), an instrument based on the work of McPherson [32], which has been subsequently adapted by Okuyan [33, 34] (see Additional file 2, section B). Knowledge is measured with 7 items, covering medications' names, intended purpose, intended regimen, intended route of administration, possible side effects, and course of action if side effects occur or a dose is missed. The final score is a summation of seven subscales measured on a 0 or 1 ordinal scale. High medication knowledge is defined as a score $\geq 5$.
3) Beliefs about medication: We assessed patients' perceptions and expectations about their medications using the Beliefs about Medication Questionnaire (BMQ) [35-38] (see Additional file 2, section D). The BMQ contains two separate constructs (generically referred to as the BMQSpecific subscales), namely the Medication Concerns construct and the Medication Necessity construct. The former represents the concerns of patients around the negative effects for taking their medication, and the latter their beliefs around the necessity of taking it to maintain health. These constructs are sometimes presented as a ratio or differential, although we chose to analyse them separately in this study. The Medications Concerns construct is measured with 5 of the BMQ items (e.g., "I sometimes worry about the long-term effects of my medicines", "My medicines disrupt my life"), and the Specific Necessity construct with another 5 items (e.g., "My health, at present, depends on my medicines", "Without my medicines I would be very ill"). Items are rated on 5 point subscales, from 1 = strongly disagree to $5=$ strongly agree. A combined high score in the Medications Concerns construct theme means that patients are worried about potential adverse effects of their medications. Conversely, a combined high score in Specific Necessity construct means that patients think their medications are important to them. An additional statement of concern (not included in the Specific Concern construct) is included in the BMQ that asks patients whether they believe their medications to be causing unpleasant side effects, also rated on a 5 point subscale.

4) Illness perceptions: We assessed patients' perceptions about their health problems using the Brief Illness Perception Questionnaire (BIPQ), an instrument based on the work of Weinman [39] and then Moss-Morris [40], later adapted by Broadbent [41] (see Additional file 2, section E). The BIPQ is a 9-item scale, assessing illness perceptions across 4 interrelated dimensions: cognitive illness representations (items 1-5), emotional illness representations (items 6-8), illness comprehensibility (item 7) and causal representation (item 9). Items are rated on an 11-point Likert-like scale. The BIPQ can be scored in multiple ways, as individual items, as a score within each of the 4 dimensions, or as a total score [41-43]. In the case of scoring, subscales relating to items 3, 4, and 7 should be reversed (Personal communication E Broadbent 15 Jan 2015).

5) Additional qualitative questions were incorporated to supplement some of the study aims (see Additional file 2 , Section $\mathrm{H}$ ). These questions were developed 
after a literature review, brainstorming by the research team, and discussions with nephrology healthcare professionals within the CMDHB programme.

\section{Reliability of study instruments}

We assessed the reliability of the psychometric instruments by their internal consistency. Internal consistency was defined by the Cronbach's $\alpha$ statistic, using a score of 0.7 or larger as indicative of a strong level of internal consistency amongst items in the scale, and a score of $<0.5$ as being indicative of poor internal consistency [44]. Results of the reliability analysis are reported in Table 2. The Cronbach's $\alpha$ for item subscales within medication adherence, BMQ-specific medication necessity, BMQ-specific medication concerns, and health literacy were $0.77,0.71,0.78$, and 0.78 respectively. This is indicative of strong level of internal consistency amongst subscales, and supports the retention of all items within each construct. The Cronbach's $\alpha$ for the subscales within medication knowledge, however, was 0.44 due to the outlying item B7 (See Additional file 2, Section B). By dropping this item from the construct, the Cronbach's $\alpha$ improved to 0.63 , which is closer but nonetheless slightly short of the suggested threshold of 0.7. Despite this marginal internal consistency, a considered judgement was adopted to retain all times in the construct other than for B7. Additionally, Nunally provides support a threshold for Cronbach's $\alpha$ above 0.6 as being acceptable in the case of an exploratory study [45].

The internal consistency of the subscales for the BIPQ emotional and cognitive dimensions were poor, although the reliability of subscales within the cognitive dimension improved a little by dropping the outlying items E2 and E4 (See Additional file 2, Section E). Even after these manoeuvres, however, Cronbach's $\alpha$ did not reach the acceptable threshold of 0.6 .

\section{Distribution of scores for psychometric constructs}

We assessed the scores from the MMAS- 8 and psychometric constructs for normality, skewness and kurtosis. A strictly quantitative description of the various scores is provided in Table 3, without any accompanying interpretation or insights. Inspection of the z-scores for both the kurtosis criteria suggest the scores are well within the $+/-1.96$ cutoff points $(p \leq 0.05)$ for normality [46]. The z-scores for skewness are below the $+/-1.96(p \leq 0.05)$ criteria for the knowledge and concerns scores, while the necessity and total adherence scores for skewness are below the $+/-2.58$ cut-off $(p \leq 0.01)$. Since a sample of 100 fits within the guideline of a small sample, the skewness scores suggest that the dataset is borderline but acceptable for least squares regression, especially in the context of multivariate data analysis [47].

\section{Statistical analysis}

Simple comparisons will be made by Chi-square test, Student's $t$-test or their non-parametric equivalents as appropriate. Exploratory modelling will be performed using multivariate regression analysis, using a number of specific techniques. These will include conventional regression analysis, and also mediation, moderation, and conditional process analysis (see an example in Fig. 1) [48]. Scores for psychometric constructs can be modelled as either continuous variables (where higher scores indicate stronger beliefs or perceptions in the construct represented by the scale), or by dichotomizing at the scale midpoint or some other point of discrimination [37]. While the latter is a convenient way of categorizing respondents, we will attempt to use the continuous scale analyses as this provides richer information that is lost when scales are dichotomized. Statistical significance of associations will be attributed to findings if the twotailed $P$ value is $<0.05$.

Qualitative data will be analyzed using a general inductive/thematic approach [49].

\section{Ethical considerations}

The study protocol has been reviewed and approved by the National (NZ) Health and Disability Ethics Committee (IORG0000895) and the Counties Manukau Institutional Review Board (FWA00021560), and the University of Auckland Human Participants Ethics Committees (IRB00009352). Informed consent was gained from all participants.

\section{Discussion}

This study will provide important information on the factors involved in medication non-adherence in New Zealand dialysis patients. The resulting knowledge will inform longterm initiatives to reduce medication non-adherence in dialysis patients, and help ensure that they are addressing appropriate and evidence based targets for intervention.

Important strengths of this study include the use of well-validated study instruments, and a study sample that is inclusive of different ethnicities and importantly modalities/locations of dialysis. These will allow us to model links between demographics, environment, and psychometric characteristics when assessing their individual effects on medication adherence. However, there are several limitations of this study. Firstly, the study design is based upon interviewing each patient about one medication that they are taking, a pragmatic compromise that was accepted by the research team given the diversity of different medication regimens in the study sample. It is possible that adherence will differ between different types of medication, which is something that cannot be assessed in this study, and could conceivably be a source of unmeasured confounding. 
Table 2 Internal consistency of construct item subscales

\begin{tabular}{|c|c|c|c|c|c|c|}
\hline Construct & $\begin{array}{l}\text { Instrument } \\
\text { item }\end{array}$ & $\begin{array}{l}\text { Subscale mean } \\
\text { if item deleted }\end{array}$ & $\begin{array}{l}\text { Subscale variance } \\
\text { if item deleted }\end{array}$ & $\begin{array}{l}\text { Corrected item- } \\
\text { total correlation }\end{array}$ & $\begin{array}{l}\text { Squared multiple } \\
\text { correlation }\end{array}$ & $\begin{array}{l}\text { Cronbach's a } \\
\text { if item deleted }\end{array}$ \\
\hline \multirow[t]{8}{*}{ Medical Adherence Cronbach's $a=0.77$} & $\mathrm{C} 1$ & 5.08 & 3.43 & 0.57 & 0.40 & 0.72 \\
\hline & $\mathrm{C} 2$ & 4.79 & 3.58 & 0.49 & 0.27 & 0.74 \\
\hline & $\mathrm{C} 3$ & 4.66 & 3.90 & 0.39 & 0.28 & 0.75 \\
\hline & C4 & 4.79 & 3.66 & 0.44 & 0.25 & 0.75 \\
\hline & C5 & 4.53 & 4.17 & 0.40 & 0.19 & 0.76 \\
\hline & $\mathrm{C} 6$ & 4.63 & 3.71 & 0.56 & 0.41 & 0.73 \\
\hline & C7 & 4.76 & 3.76 & 0.40 & 0.21 & 0.75 \\
\hline & $\mathrm{C} 8$ & 4.91 & 3.50 & 0.51 & 0.39 & 0.73 \\
\hline \multirow[t]{3}{*}{ Health Literacy Cronbach's $a=0.78$} & F1 & 5.45 & 7.62 & 0.62 & 0.39 & 0.70 \\
\hline & $\mathrm{F} 2$ & 4.84 & 7.69 & 0.60 & 0.36 & 0.72 \\
\hline & F3 & 5.45 & 8.23 & 0.64 & 0.41 & 0.69 \\
\hline \multirow{7}{*}{$\begin{array}{l}\text { Medication Knowledge (Original) } \\
\text { Cronbach's } a=0.44\end{array}$} & B1 & 4.45 & 0.90 & 0.27 & 0.39 & 0.37 \\
\hline & B2 & 4.14 & 0.91 & 0.26 & 0.18 & 0.38 \\
\hline & B3 & 3.83 & 1.15 & 0.51 & 0.62 & 0.34 \\
\hline & B4 & 3.86 & 1.12 & 0.36 & 0.51 & 0.36 \\
\hline & B5 & 4.69 & 1.08 & 0.33 & 0.24 & 0.35 \\
\hline & B6 & 3.90 & 1.03 & 0.42 & 0.35 & 0.31 \\
\hline & B7 & 3.90 & 1.60 & -0.39 & 0.24 & 0.63 \\
\hline \multirow{6}{*}{$\begin{array}{l}\text { Medication Knowledge }-(\text { Modified, B7 } \\
\text { omitted) Cronbach's a }=0.63\end{array}$} & B1 & 3.55 & 0.97 & 0.41 & 0.28 & 0.57 \\
\hline & B2 & 3.24 & 1.05 & 0.32 & 0.16 & 0.62 \\
\hline & B3 & 2.93 & 1.35 & 0.48 & 0.62 & 0.58 \\
\hline & B4 & 2.97 & 1.32 & 0.35 & 0.51 & 0.59 \\
\hline & B5 & 3.79 & 1.24 & 0.37 & 0.24 & 0.58 \\
\hline & B6 & 3.00 & 1.21 & 0.42 & 0.35 & 0.57 \\
\hline \multirow{5}{*}{$\begin{array}{l}\text { Beliefs about Medication - Medical Necessity } \\
\text { Cronbach's } a=0.71\end{array}$} & D1 & 16.93 & 5.96 & 0.42 & 0.23 & 0.73 \\
\hline & D3 & 17.20 & 4.12 & 0.61 & 0.40 & 0.66 \\
\hline & D4 & 16.87 & 5.39 & 0.47 & 0.33 & 0.71 \\
\hline & D7 & 17.06 & 5.27 & 0.58 & 0.38 & 0.67 \\
\hline & D10 & 16.94 & 6.06 & 0.51 & 0.31 & 0.70 \\
\hline \multirow{5}{*}{$\begin{array}{l}\text { Beliefs about Medication - Medical Concerns } \\
\text { Cronbach's } a=0.78\end{array}$} & D2 & 11.27 & 13.57 & 0.54 & 0.33 & 0.74 \\
\hline & D5 & 10.67 & 12.47 & 0.61 & 0.40 & 0.72 \\
\hline & D6 & 11.05 & 13.89 & 0.49 & 0.27 & 0.76 \\
\hline & D8 & 11.46 & 14.09 & 0.54 & 0.30 & 0.74 \\
\hline & D9 & 10.91 & 13.92 & 0.60 & 0.36 & 0.73 \\
\hline \multirow{5}{*}{$\begin{array}{l}\text { Illness Perception - Cognitive (Original) } \\
\text { Cronbach's } a=0.41\end{array}$} & E1 & 18.9 & 37.4 & 0.31 & 0.16 & 0.28 \\
\hline & E2 & 17.0 & 46.6 & 0.10 & 0.04 & 0.44 \\
\hline & $E 3^{\mathrm{a}}$ & 22.2 & 32.4 & 0.38 & 0.16 & 0.20 \\
\hline & $E 4^{a}$ & 24.9 & 52.7 & 0.03 & 0.04 & 0.45 \\
\hline & E5 & 20.2 & 37.0 & 0.22 & 0.11 & 0.36 \\
\hline \multirow{4}{*}{$\begin{array}{l}\text { Illness Perception - Cognitive (Modified, E2 } \\
\text { omitted) Cronbach's } a=0.44\end{array}$} & E1 & 10.1 & 29.5 & 0.30 & 0.15 & 0.32 \\
\hline & $E 3^{\mathrm{a}}$ & 13.4 & 24.9 & 0.37 & 0.15 & 0.22 \\
\hline & $E 4^{\mathrm{a}}$ & 16.1 & 43.5 & 0.02 & 0.04 & 0.52 \\
\hline & E5 & 11.4 & 26.5 & 0.29 & 0.09 & 0.33 \\
\hline
\end{tabular}


Table 2 Internal consistency of construct item subscales (Continued)

\begin{tabular}{|c|c|c|c|c|c|c|}
\hline \multirow{4}{*}{$\begin{array}{l}\text { Illness Perception - Cognitive (Modified, E4 } \\
\text { omitted) Cronbach's a =0.45 }\end{array}$} & E1 & 18.1 & 32.9 & 0.37 & 0.14 & 0.28 \\
\hline & E2 & 16.1 & 43.5 & 0.09 & 0.04 & 0.52 \\
\hline & $\mathrm{E}^{\mathrm{a}}$ & 21.3 & 30.4 & 0.35 & 0.13 & 0.28 \\
\hline & E5 & 19.3 & 33.5 & 0.23 & 0.11 & 0.41 \\
\hline \multirow{3}{*}{$\begin{array}{l}\text { Illness Perception - Cognitive (Modified, E2 } \\
\text { and E4 omitted) Cronbach's a = } 0.52\end{array}$} & E1 & 9.2 & 25.4 & 0.35 & 0.13 & 0.38 \\
\hline & $E 3^{\mathrm{a}}$ & 12.5 & 23.2 & 0.34 & 0.12 & 0.41 \\
\hline & E5 & 10.5 & 23.3 & 0.31 & 0.09 & 0.46 \\
\hline \multirow{2}{*}{$\begin{array}{l}\text { Illness Perception - Emotional Cronbach's } \\
a=0.52\end{array}$} & E6 & 5.90 & 10.1 & 0.35 & 0.12 & $\mathrm{n} / \mathrm{a}$ \\
\hline & E8 & 6.90 & 12.0 & 0.35 & 0.12 & $\mathrm{n} / \mathrm{a}$ \\
\hline
\end{tabular}

${ }^{\mathrm{a} S c a l e}$ reversed for these items (Personal communication E. Broadbent 15 Jan 2015

Secondly, the sample size is modest, especially given the diversity of the sample population. Notwithstanding, 100 participants is probably adequate given the novel regression techniques that are planned, where we will model 3 or 4 variables as either instrumental or mediating factors, and the rest as effect modifiers. Finally, the qualitative interviews were not recorded because of feasibility/resource constraints, and also because this part of the study was to supplement study aims that (in the great majority) were being addressed by the survey tool. In an ideal world, verbatim transcription of recorded interviews would be undertaken, as is the standard recommended practice. This compromise can be expected to reduce the strength and number of insights from the qualitative portion of the study.

Patient-related factors are well known to influence medication adherence. Some of these factors are purely unintentional; such as personality, attentional and coping style, comprehension difficulties, access to medications

Table 3 Summary of scores for the final constructs of medication adherence, medication knowledge, health literacy, beliefs about medication, and illness perception, reported as mean (standard deviation)

\begin{tabular}{|c|c|}
\hline Construct & Score \\
\hline Medication adherence & $5.5(2.2)$ \\
\hline Medication knowledge & $4.3(1.5)$ \\
\hline Health literacy ${ }^{\mathrm{a}}$ & $2.6(1.3)$ \\
\hline \multicolumn{2}{|c|}{ Beliefs about medication (BMQ) } \\
\hline Medication necessity & $21.3(2.8)$ \\
\hline Medication concerns & $13.8(4.5)$ \\
\hline \multicolumn{2}{|l|}{ IIIness perception (BIPQ) ${ }^{b}$} \\
\hline Cognitive dimension & $32.2(5.6)$ \\
\hline Emotional dimension & $12.8(5.5)$ \\
\hline Illness comprehensibility & $2.02(2.8)$ \\
\hline
\end{tabular}

etc. $[50,51]$. Other factors are intentional, and some of these relate closely to patient perceptions (Table 4). Patients' pre-existing beliefs about illness and medical treatment are likely to affect their motivation to adhere to prescribed treatment [40]. Traditionally research has focused on perceptions of the need for treatment and concerns about potential adverse effects (the necessityconcerns framework) [52]. Within this framework, a stronger perception of necessity for treatment is associated with higher adherence across disparate patient groups with chronic diseases. Similarly, fewer concerns about treatment are also associated with greater adherence [52, 53]. These perceptions may be influenced by factors such as ethnicity and cultural beliefs, [54] health literacy and other psychosocial factors [13]. Limited health literacy is particularly widespread in dialysis patients, and

a)

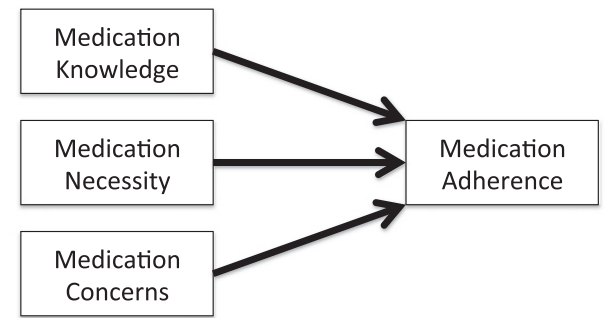

b)

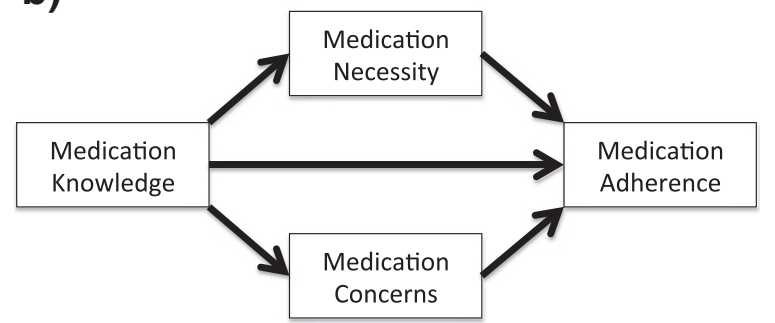

Fig. 1 Examples of extended regression analyses planned for these study data. Panel (a) exemplifies conventional regression analysis, and panel (b) exemplifies mediation regression analysis 
Table 4 Examples of possible reasons for medication non-adherence with potential risk factors and intervention strategies

\begin{tabular}{|c|c|c|c|}
\hline \multicolumn{2}{|c|}{ Example reasons for medication non-adherence } & \multirow{2}{*}{$\begin{array}{l}\text { Possible risk factors } \\
\text { Financial restrictions }\end{array}$} & \multirow{2}{*}{$\begin{array}{l}\text { Possible intervention strategy } \\
\text { Social support }\end{array}$} \\
\hline Unintentional & Difficulty with access to medications & & \\
\hline & & Socioeconomic & Government support \\
\hline & Poor comprehension & Language barriers & Multi-lingual information availability \\
\hline & & Literacy & Translators \\
\hline & & Low education level & Family assistance \\
\hline & & Visual impairment & $\begin{array}{l}\text { Evaluation of available materials } \\
\text { and development of new resources }\end{array}$ \\
\hline & Forgetting medications & Attention style & Family support \\
\hline & & Poor cognitive function & Physical or electronic reminders \\
\hline & & & Blister packed medications \\
\hline & Poor tolerability & Pill burden & Minimise dosing where possible \\
\hline & & Frequent dosing & Simplify drug regimen \\
\hline \multirow[t]{6}{*}{ Intentional or related to health beliefs } & \multirow{4}{*}{$\begin{array}{l}\text { Low perception of } \\
\text { medication importance }\end{array}$} & Low health literacy & Education \\
\hline & & Age & Health psychology/psychiatry input \\
\hline & & Depression & Culturally appropriate information \\
\hline & & Cultural beliefs & Establishing goals of treatment \\
\hline & \multirow{2}{*}{$\begin{array}{l}\text { High perception of potential } \\
\text { harm from medications }\end{array}$} & Low health literacy & Education \\
\hline & & Cultural beliefs & Culturally appropriate information \\
\hline
\end{tabular}

associated with reduced access to healthcare $[55,56]$. Health literacy is a direct and indirect determinant of medication adherence, and improving literacy may afford clinician better opportunities to communicate with patients about their medication $[57,58]$. The impact of environmental factors, for instance the location and modality of dialysis, are not as well understood in regards to the extent to which they influence medication adherence $[59,60]$. In general, environmental factors are potentially more amenable to modification than patient factors, and are therefore important to investigate. Despite this, interventions to improve medication adherence often address patient-related barriers, and less often condition, therapy, and socioeconomic factors [61]. For instance, medication reconciliation exercises often stall at initiation, as patients are unable to recall the names of their medications. A potentially inexpensive strategy for this problem may be to simplify medication names to improve pill identification [62].

There is limited evidence for strategies to improve adherence to therapy in dialysis patients. In a systematic review of trials to improve general adherence to treatment in haemodialysis patients, Matteson and Russell summarized 8 trials, finding that $6 / 8$ trials found modest improvements in adherence with intervention, and that most successful interventions relied on cognitive or cognitive/behavioural intervention strategies [12]. Overall evidence was however limited by small sample size, homogenous samples, short intervention periods and a high baseline rate of poor adherence.
Current health outcomes for patients on dialysis are significantly poorer than that of the general population, with a median survival after dialysis inception of 4.2 years in New Zealand [63] and a significantly impaired quality of life [64]. Given the high prevalence of medication non-adherence in dialysis patients and the potential for improved outcomes [10], improving our knowledge about factors involved in medication adherence in these patients is of vital importance.

\section{Additional files}

Additional file 1: Clinical Data Case Report Form Version 1.1 29.04.2013.

Additional file 2: In-person, interviewer-assisted questionnaire.

\section{Abbreviations}

BIPQ: Brief IIIness Perception Questionnaire; BMQ: Beliefs about Medication Questionnaire; MKET: Medication Knowledge Evaluation Tool; CKD: Chronic kidney disease; CMDHB: Counties Manukau District Health Board; NZ: New Zealand; S-TOFHLA: Short Test of Functional Health Literacy in Adults; REALM: Rapid Estimate of Adult Literacy in Medicine; MMAS-8: Morisky 8item Medication Adherence Scale.

\section{Competing interests}

Mark R Marshall is employed by Baxter Healthcare as the Director of Medical Affairs, Asia-Pacific (Renal). The other authors have no other competing interests to declare.

\section{Authors' contributions}

TA, JK, and MRM conceived the study. MJW, MRM ER and TA drafted the manuscript and performed the statistical analysis. TA, TMM, SC, DK, SL, KP, OT, and PT collected the data. ALK and JSS managed patient selection and data collection. All authors read and approved the final manuscript. 


\section{Authors' information}

TA and JK are a lecturer and professor at the School of Pharmacy, Faculty of Medical and Health Sciences, University of Auckland, Auckland, New Zealand. MJW is a PhD student at the School of Medicine, University of Queensland, Brisbane, Australia. MRM is an adjunct associate professor at the School of Medicine, Faculty of Medical and Health Sciences, University of Auckland, Auckland, New Zealand. TMM is a research fellow at the Department of Renal Medicine, Counties Manukau District Health Board, Auckland, New Zealand. SC, DK, SL, KP, OT, and PT are BPharm students at the School of Pharmacy, Faculty of Medical and Health Sciences, University of Auckland, Auckland, New Zealand. ALK is a pharmacist at Pharmacy Services, Counties Manukau District Health Board, Auckland, New Zealand. JSS is a nephrology fellow at the Department of Renal Medicine, Counties Manukau District Health Board, Auckland, New Zealand.

\section{Acknowledgements}

Funding for this project was provided predominantly by a Jacquot Research Establishment Award from the Royal Australasian College of Physicians. Additional funds were also provided by the School of Pharmacy at the University of Auckland. We would also like to acknowledge the input of the Māori Cultural Resource Unit at CMDHB, Associate Professor Papaarangi Reid from the University of Auckland and Susan Reid from Workbase for their advice regarding this study.

\section{Author details}

${ }^{1}$ School of Pharmacy, Faculty of Medical and Health Sciences, The University of Auckland, 85 Park Rd, Auckland 1142, New Zealand. ${ }^{2}$ School of Medicine, University of Queensland, 288 Herston Road, Brisbane 4006, Australia. ${ }^{3}$ Department of Renal Medicine, Counties Manukau District Health Board, Hospital Road, Otahuhu, Auckland 1640, New Zealand. ${ }^{4}$ Marketing Department, Faculty of Business, Auckland University of Technology, 46 Wakefield St, Auckland 1010, New Zealand. ${ }^{5}$ Formerly of the School of Pharmacy, Faculty of Medical and Health Sciences, The University of Auckland, 85 Park Rd, Auckland 1142, New Zealand. ${ }^{6}$ Pharmacy Services, Counties Manukau District Health Board, Hospital Road, Otahuhu, Auckland 1640, New Zealand. ${ }^{7}$ School of Medicine, Faculty of Medical and Health Sciences, The University of Auckland, 85 Park Rd, Auckland 1142, New Zealand.

\section{Received: 20 October 2014 Accepted: 25 June 2015}

Published online: 11 July 2015

\section{References}

1. Osterberg L, Blaschke T. Adherence to Medication. N Engl J Med. 2005;353(5):487-97.

2. Viswanathan M, Golin CE, Jones CD, Ashok M, Blalock SJ, Wines RCM, et al. Interventions to improve adherence to self-administered medications for chronic diseases in the United States: a systematic review. Ann Intern Med. 2012;157(11):785-95.

3. DiMatteo MR, Giordani PJ, Lepper HS, Croghan TW. Patient adherence and medical treatment outcomes: a meta-analysis. Med Care. 2002;40(9):794-811.

4. Granger BB, Swedberg K, Ekman I, Granger CB, Olofsson B, McMurray JJV, et al. Adherence to candesartan and placebo and outcomes in chronic heart failure in the CHARM programme: double-blind, randomised, controlled clinical trial. Lancet. 2005;366(9502):2005-11.

5. Bitton A, Choudhry NK, Matlin OS, Swanton K, Shrank WH. The impact of medication adherence on coronary artery disease costs and outcomes: a systematic review. Am J Med. 2013;126(4):357. e357-357.e327.

6. Chiu Y-W, Teitelbaum I, Misra M, de Leon EM, Adzize T, Mehrotra R. Pill burden, adherence, hyperphosphatemia, and quality of life in maintenance dialysis patients. Clin J Am Soc Nephrol. 2009;4(6):1089-96.

7. Manley HJ, Garvin CG, Drayer DK, Reid GM, Bender WL, Neufeld TK, et al. Medication prescribing patterns in ambulatory haemodialysis patients: comparisons of USRDS to a large not-for-profit dialysis provider. Nephrol Dial Transplant. 2004;19(7):1842-8.

8. Schmid H, Hartmann B, Schiffl $H$. Adherence to prescribed oral medication in adult patients undergoing chronic hemodialysis: a critical review of the literature. Eur J Med Res. 2009;14(5):185-90.

9. Mirkov S. Implementation of a pharmacist medication review clinic for haemodialysis patients. N Z Med J. 2009;122(1297):25-37.
10. Weinhandl ED, Arneson TJ, St Peter WL. Clinical outcomes associated with receipt of integrated pharmacy services by hemodialysis patients: a quality improvement report. Am J Kidney Dis. 2013;62(3):557-67.

11. Kripalani S, Yao X, Haynes R. Interventions to enhance medication adherence in chronic medical conditions: A systematic review. Arch Intern Med. 2007;167(6):540-9.

12. Matteson ML, Russell C. Interventions to improve hemodialysis adherence: a systematic review of randomized-controlled trials. Hemodial Int. 2010;14(4):370-82

13. Browne T, Merighi JR. Barriers to adult hemodialysis patients' selfmanagement of oral medications. Am J Kidney Dis. 2010;56(3):547-57.

14. Grace B, Hurst K, McDonald S, Clayton P. Stock and Flow. In: Clayton P, McDonald S, Hurst K, editors. ANZDATA Registry. 36th Report, 2013. Adelaide, Australia: Australia and New Zealand Dialysis and Transplant Registry; 2014;1-8.

15. Green SB. How Many Subjects Does It Take To Do A Regression Analysis? Multivar Behav Res. 1991;26(3):499-510.

16. Tabachnick BG, Fiddel LS. Using Multivariate Statistics. 5th ed. Boston, MA: Pearson/Allyn \& Bacon; 2007.

17. Morisky DE, Ang A, Krousel-Wood M, Ward HJ. Predictive validity of a medication adherence measure in an outpatient setting. J Clin Hypertens. 2008;10(5):348-54.

18. Al-Qazaz H, Hassali MA, Shafie AA, Sulaiman SA, Sundram S, Morisky DE. The eight-item Morisky Medication Adherence Scale MMAS: translation and validation of the Malaysian version. Diabetes Res Clin Pract. 2010;90(2):216-21.

19. Krousel-Wood M, Islam T, Muntner P, Holt E, Joyce C, Morisky DE, et al. Association of depression with antihypertensive medication adherence in older adults: cross-sectional and longitudinal findings from CoSMO. Ann Behav Med. 2010;40(3):248-57.

20. Oliveira-Filho AD, Barreto-Filho JA, Neves SJ, Lyra Junior DP. Association between the 8-item Morisky Medication Adherence Scale (MMAS-8) and blood pressure control. Arq Bras Cardiol. 2012:99(1):649-58.

21. Ministry of Health. Ethnicity Data Protocols for the Health and Disability Sector. Wellington: Ministry of Health; 2004.

22. Tan L, Blakely T, Atkinson J. Ethnic counts on mortality and census data 2001-06: New Zealand census-mortality study update. N Z Med J. 2010;123(1320):37-44.

23. Cormack D. Making ethnicity data count. Best Pract J. 2007;9:44-6.

24. Salmond CE, Crampton P. Development of New Zealand's deprivation index (NZDep) and its uptake as a national policy tool. Can J Public Health. 2012;103(8 Suppl 2):S7-11.

25. Charlson ME, Pompei P, Ales KL, MacKenzie CR. A new method of classifying prognostic comorbidity in longitudinal studies: development and validation. J Chronic Dis. 1987:40(5):373-83.

26. Hall WH, Ramachandran $R$, Narayan S, Jani AB, Vijayakumar S. An electronic application for rapidly calculating Charlson comorbidity score. BMC Cancer. 2004:4:94.

27. Brice JH, Foster MB, Principe S, Moss C, Shofer FS, Falk RJ, et al. Single-item or two-item literacy screener to predict the S-TOFHLA among adult hemodialysis patients. Patient Educ Couns. 2014:94(1):71-5.

28. Jain D, Sheth H, Bender FH, Weisbord SD, Green JA. Evaluation of a single-item screening question to detect limited health literacy in peritoneal dialysis patients. Adv Perit Dial. 2014;30:27-30.

29. Wallace LS, Rogers ES, Roskos SE, Holiday DB, Weiss BD. Brief report: screening items to identify patients with limited health literacy skills. J Gen Intern Med. 2006;21(8):874-7.

30. Chew LD, Griffin JM, Partin MR, Noorbaloochi S, Grill JP, Snyder A, et al. Validation of screening questions for limited health literacy in a large VA outpatient population. J Gen Intern Med. 2008:23(5):561-6.

31. Marshall MR, Rajah E, Wolley M, Reid S, Aspden T. Validation of a 3-item health literacy screener in a multiethnic New Zealand dialysis population. Nephrol Dial Transplant. In Press.

32. McPherson ML, Smith SW, Powers A, Zuckerman $\mathrm{H}_{\text {. }}$. Association between diabetes patients' knowledge about medications and their blood glucose control. Res Social Adm Pharm. 2008;4(1):37-45.

33. Okuyan B, Sancar M, Izzettin FV. Assessment of medication knowledge and adherence among patients under oral chronic medication treatment in community pharmacy settings. Pharmacoepidemiol Drug Saf. 2013;22(2):209-14.

34. Okuyan B, Sancar M, Izzettin FV, Morisky DE. Erratum to and corrections on the article entitled "Assessment of medication knowledge and adherence among patients under oral chronic medication treatment in community pharmacy settings". Pharmacoepidemiol Drug Saf. 2013;22(2):218-20. 
35. Ernst FR, Grizzle AJ. Drug-related morbidity and mortality: updating the cost-of-illness model. J Am Pharm Assoc. 2001;41(2):192-9.

36. Horne R. Patients' beliefs about treatment: the hidden determinant of treatment outcome? J Psychosom Res. 1999:47(6):491-5.

37. Horne R, Weinman J. Patients' beliefs about prescribed medicines and their role in adherence to treatment in chronic physical illness. J Psychosom Res. 1999;47(6):555-67.

38. Horne R, Weinman J, Hankins M. The beliefs about medicines questionnaire: The development and evaluation of a new method for assessing the cognitive representation of medication. Psychol Health. 1999;14(1):1-24.

39. Weinman J, Petrie KJ, Moss-morris R, Horne R. The illness perception questionnaire: A new method for assessing the cognitive representation of illness. Psychol Health. 1996;11(3):431-45.

40. Moss-Morris R, Weinman J, Petrie KJ, Horne R, Ceameron LD, Buick D. The Revised IIIness Perception Questionnaire (IPQ-R. Psychol Health. 2002;17:1-16.

41. Broadbent E, Petrie KJ, Main J, Weinman J. The brief illness perception questionnaire. J Psychosom Res. 2006;60(6):631-7.

42. Iskandarsyah A, de Klerk C, Suardi DR, Sadarjoen SS, Passchier J. Consulting a traditional healer and negative illness perceptions are associated with non-adherence to treatment in Indonesian women with breast cancer. Psycho-Oncology. 2014;23(10):1118-24.

43. Pesut DP, Bursuc BN, Bulajic MV, Solovic I, Kruczak K, Duarte R, et al. Illness perception in tuberculosis by implementation of the Brief Illness Perception Questionnaire - a TBNET study. SpringerPlus. 2014;3:664.

44. Hair JF, Black WC, Babin B, Anderson RE, Tatham RL. Multivariate Data Analysis. Upper Saddle River, NJ: Prentice Hall; 2006.

45. Nunnally JC, Bernstein IH. Psychometric Theory. 3rd ed. New York: McGraw-Hill; 1994.

46. Field AP. Discovering statistics using SPSS. Thousand Oaks, CA: SAGE publications Ltd; 2009.

47. Tabachnick BG, Fidell LS. Using Multivariate Statistics. 6th ed. Boston: Pearson; 2012.

48. Hayes AF. Introduction to mediation, moderation and conditional process analysis: a regression based approach. New York: The Guildford Press; 2013.

49. Thomas DR. A General Inductive Approach for Analyzing Qualitative Evaluation Data. Am J Eval. 2006;27(2):237-46.

50. Christensen AJ, Moran PJ, Lawton WJ, Stallman D, Voigts AL. Monitoring attentional style and medical regimen adherence in hemodialysis patients. Health Psychol. 1997;16(3):256-62.

51. Christensen AJ, Smith TW. Personality and patient adherence: correlates of the five-factor model in renal dialysis. J Behav Med. 1995;18(3):305-13.

52. Horne R, Chapman SCE, Parham R, Freemantle N, Forbes A, Cooper V. Understanding patients' adherence-related beliefs about medicines prescribed for long-term conditions: a meta-analytic review of the Necessity-Concerns Framework. PLoS ONE. 2013;8(12):e80633.

53. Neri L, Martini A, Andreucci VE, Gallieni M, Rey LAR, Brancaccio D, et al. Regimen complexity and prescription adherence in dialysis patients. Am J Nephrol. 2011;34(1):71-6.

54. Horne R, Graupner L, Frost S, Weinman J, Wright SM, Hankins M. Medicine in a multi-cultural society: the effect of cultural background on beliefs about medications. Soc Sci Med. 2004;59(6):1307-13.

55. Williams MV, Parker RM, Baker DW, Parikh NS, Pitkin K, Coates WC, et al. Inadequate functional health literacy among patients at two public hospitals. JAMA. 1995;274(21):1677-82

56. Grubbs V, Gregorich SE, Perez-Stable EJ, Hsu C-Y. Health literacy and access to kidney transplantation. Clin J Am Soc Nephrol. 2009;4(1):195-200

57. Zhang NJ, Terry A, McHorney CA. Impact of health literacy on medication adherence: a systematic review and meta-analysis. Ann Pharmacother. 2014:48(6):741-51

58. Bains SS, Egede LE. Associations between health literacy, diabetes knowledge, self-care behaviors, and glycemic control in a low income population with type 2 diabetes. Diabetes Technol Ther. 2011;13(3):335-41.

59. Karamanidou C, Clatworthy J, Weinman J, Horne R. A systematic review of the prevalence and determinants of nonadherence to phosphate binding medication in patients with end-stage renal disease. BMC Nephrol. 2008;9:2.

60. Christensen AJ, Smith TW, Turner CW, Cundick KE. Patient adherence and adjustment in renal dialysis: a person $\mathrm{x}$ treatment interactive approach. J Behav Med. 1994;17(6):549-66.
61. AlGhurair SA, Hughes CA, Simpson SH, Guirguis LM. A systematic review of patient self-reported barriers of adherence to antihypertensive medications using the world health organization multidimensional adherence model. J Clin Hypertens. 2012;14(12):877-86.

62. Bailey SC, Wolf MS, Lopez A, Russell A, Chen AH, Schillinger D, et al. Expanding the Universal Medication Schedule: a patient-centred approach. BMJ Open. 2014;4(1):e003699.

63. Marshall MR, Walker RC, Polkinghorne KR, Lynn KL. Survival on home dialysis in New Zealand. PLoS ONE. 2014;9(5):e96847.

64. Wyld M, Morton RL, Hayen A, Howard K, Webster AC. A systematic review and meta-analysis of utility-based quality of life in chronic kidney disease treatments. PLoS Med. 2012;9(9):e1001307.

\section{Submit your next manuscript to BioMed Central and take full advantage of:}

- Convenient online submission

- Thorough peer review

- No space constraints or color figure charges

- Immediate publication on acceptance

- Inclusion in PubMed, CAS, Scopus and Google Scholar

- Research which is freely available for redistribution 